\title{
Post-operative pain after laparoscopic right hemicolectomy for Crohn's disease: a case control study
}

\author{
K. McKevitt', S.M. Sahebally', S. Patchett', A. O’'Toole', S. Galvin², J.P. Burke ${ }^{16}$ \\ (1) Departments of Colorectal Surgery ; (2) Gastroenterology ; (3) Anaesthesia, Beaumont Hospital, Dublin 9, Ireland.
}

\begin{abstract}
Aim : Surgery for Crohn's disease (CD) is characterized by an enhanced inflammatory response. While inflammation can induce hyperalgesia, post-operative pain following surgery for CD has not been characterized. This retrospective study compared a consecutive series of patients undergoing laparoscopic right hemicolectomy for $\mathrm{CD}$ and neoplasia performed by a single surgeon.

Method : Elective resections performed between Jan-2016 and Aug-2017 managed in an enhanced recovery pathway were eligible for inclusion. Patients were excluded if open surgery was performed, an ileostomy was fashioned, no patient-controlled analgesia (PCA) was used or data were incomplete.

Results : 38 cases were included, 20 for neoplasia and 18 for ileocolonic CD. There was no difference in patient gender $(\mathrm{P}=0.520)$. $C D$ patients were younger $(39.8 \pm 2.8 \mathrm{Vs} 77.2 \pm 2.1$ years, $P<0.001)$ but had an equivalent length of resection $(312.9 \pm 43.5 \mathrm{Vs}$ 283.3 $\pm 71.7 \mathrm{~mm}, \mathrm{P}=\mathbf{0 . 9 1 5}$ ). CD patients had higher pain scores on post-operative day $1(6.8 \pm 0.8$ Vs $2.6 \pm 1.0, P<0.001)$, day $2(5.0 \pm 0.5$ Vs $1.6 \pm 0.9, P<0.001)$ and day $3(4.1 \pm 0.6$ Vs $1.3 \pm 0.7, P=0.008)$. CD patients used their PCA for longer (85.7 \pm 16.3 Vs $47.7 \pm 4.2$ hours, $P=0.017$ ) and used a greater total amount of morphine (148.6 \pm 33.8 Vs $37.0 \pm 7.8 \mathrm{mg}, \mathrm{P}<0.001)$. Post-operative CRP was higher in patients with $\mathrm{CD}$ on day $1(\mathrm{P}=0.011)$, day $2(\mathrm{P}=0.001)$, day $3(\mathrm{P}=0.001)$ and day $4(\mathrm{P}=0.007)$, but no leak or intra-abdominal abscess occurred in either group.

Conclusions : CD patients experience increased post-operative pain, require more post-operative analgesia and have an enhanced post-operative inflammatory response. Further studies to elucidate the mechanism of this hyperalgesia and strategies to obviate it are required. (Acta gastroenterol. belg., 2021, 84, 271-274).
\end{abstract}

Key words: Crohn's disease, surgery, pain, analgesia, inflammation.

\section{Introduction}

Crohn's disease (CD) is a chronic, relapsing-remitting inflammatory disorder of the gastrointestinal tract resulting from a complex interplay between genetic, immunological, environmental and microbial factors, in turn culminating in a dysregulated mucosal immune response and compromised gut barrier function (1). Up to $75 \%$ of patients will require at least one surgical intervention (2). Despite the increasing armamentarium of drugs that dampen mucosal inflammation, the rates of intestinal resection for $\mathrm{CD}$ have not diminished (3). Surgery for CD may be compounded by an enhanced postoperative inflammatory response $(4,5)$. Pain is a common feature of inflammatory bowel disease (IBD), and its molecular mediators are present throughout the gastrointestinal tract (6). Therefore, the dysregulated inflammation characteristic of $\mathrm{CD}$ may amplify the phenomenon of visceral hyperalgesia in CD. Traditionally
CD research, has focused on immunology, genetics and the development of novel anti-inflammatory agents in an attempt to alleviate mucosal inflammation while postoperative inflammatory responses and pain following surgery for $\mathrm{CD}$ have received little investigational efforts. With this in mind, the current study aims to compare postoperative pain after laparoscopic right colectomy for $\mathrm{CD}$ and colorectal neoplasia.

\section{Materials and methods}

This was a retrospective, case-control study conducted in a single tertiary referral centre in Ireland. Institutional ethical approval for an audit was obtained. All ileocolonic CD patients who underwent elective laparoscopic ileocolic resections between January 2016 and August 2017 were evaluated and compared with a consecutive cohort who underwent laparoscopic right colectomy for right sided colonic neoplasia during the same time period. All resections were performed with 4 ports (one $11 \mathrm{~mm}$ and three $5 \mathrm{~mm}$ ) and all specimens were extracted by extending the umbilical port site. All ileocolonic anastomoses were performed using a stapled, side-to-side technique. All patients received a single dose of cefuroxime $1.5 \mathrm{~g}$ and metronidazole $500 \mathrm{mg}$ intravenously at induction and these were not continued post-operatively unless there was significant contamination during surgery.

Diagnosis of CD was made using standard clinical, endoscopic radiological and pathological findings. All patients were managed by a dedicated multidisciplinary team of gastroenterologists and colorectal surgeons specializing in the care of IBD patients. A single surgeon carried out all operations. Diagnosis of colon neoplasia was made using endoscopic, radiological and pathological findings and all patients were discussed at a multidisciplinary team meeting prior to undergoing surgery. All patients were managed in an enhanced recovery after surgery (ERAS) pathway, consisting of specific pre-operative, intra-operative and post-operative care bundles. All patients received analgesia in the form

Correspondence to : Mr. John P. Burke, Department of Colorectal Surgery, Beaumont Hospital, Dublin 9, Ireland. Phone : +353-1-8093000.

Email : johnburke@rcsi.com

Submission date : 08/08/2019

Acceptance date : 22/08/2020 
of morphine via intravenous patient controlled analgesia (PCA), with a loading dose of $10 \mathrm{mg}$, a lockout interval of 7 minutes and a 4-hour limit of 40mg. The morphine PCA was made by mixing $60 \mathrm{mg}(1 \mathrm{ml})$ of morphine with $59 \mathrm{mls}$ of normal saline to make a total volume of $60 \mathrm{mls}$, resulting in a final concentration of $1 \mathrm{mg} / \mathrm{ml}$. The primary outcome measure was post-operative pain scores on days 1-3, assessed by a specialist nurse using a numerical pain score that was recorded on the PCA anaesthesia monitoring sheet, ranging from 0 (no pain) to 10 (worst imaginable pain ever). The secondary end point was the postoperative C-reactive protein (CRP) level on days 1-5. Patients were excluded from the study if they underwent emergency surgery, open or hand-assisted laparoscopic surgery, if a stoma was fashioned, if no PCA was used post-operatively or if data were missing. Data including patient demographics, age at diagnosis of $\mathrm{CD}$ and age at surgery, indication for surgery, American Society of Anesthesiologist (ASA) score, post-operative VAS scores, pre- and post-operative CRP levels, length of resected specimens, pre-operative pharmacotherapy and post-operative morbidity according to DindoClavien classification were retrieved from chart reviews, operation notes, pathology reports and/or pathological archived specimens (7).

\section{Statistical analysis}

Data was analyzed using SPSS v19 (SPSS Inc., Chicago, IL, USA) and presented as mean+/-standard deviation (SD) and ' $n$ ' represented the number of patients included in the analysis. Fisher's exact test was used to determine correlation between categorical variables, while continuous variables were assessed using analysis of variance (ANOVA). A p value $<0.05$ was considered significant.

\section{Results}

\section{Patient population}

The study cohort comprised 18 CD (10 males; 8 females) and 20 patients with neoplasia (12 males; 8 females) over the 19-month period. Baseline characteristics are summarised in Table 1. CD patients were significantly younger $(39.8 \pm 2.8$ Vs $77.2 \pm 2.1$ years, $\mathrm{P}<0.001$ ) but had an equivalent length of resection (312.9 \pm 43.5 Vs $283.3 \pm 71.7 \mathrm{~mm}, \mathrm{P}=0.915)$. In the $\mathrm{CD}$ cohort, the commonest pre-operative medication were biologics (83\%), followed by corticosteroids (55\%). There was an equal distribution of stricturing (50\%) and fistulating $(50 \%)$ disease patterns.

\section{Post-operative pain scores}

$\mathrm{CD}$ patients had higher pain scores on post-operative day $1(6.8 \pm 0.8$ Vs $2.6 \pm 1.0, \mathrm{P}<0.001)$, day $2(5.0 \pm 0.5$ Vs $1.6 \pm 0.9, \mathrm{P}<0.001)$ and day $3(4.1 \pm 0.6 \mathrm{Vs} 1.3 \pm 0.7$,

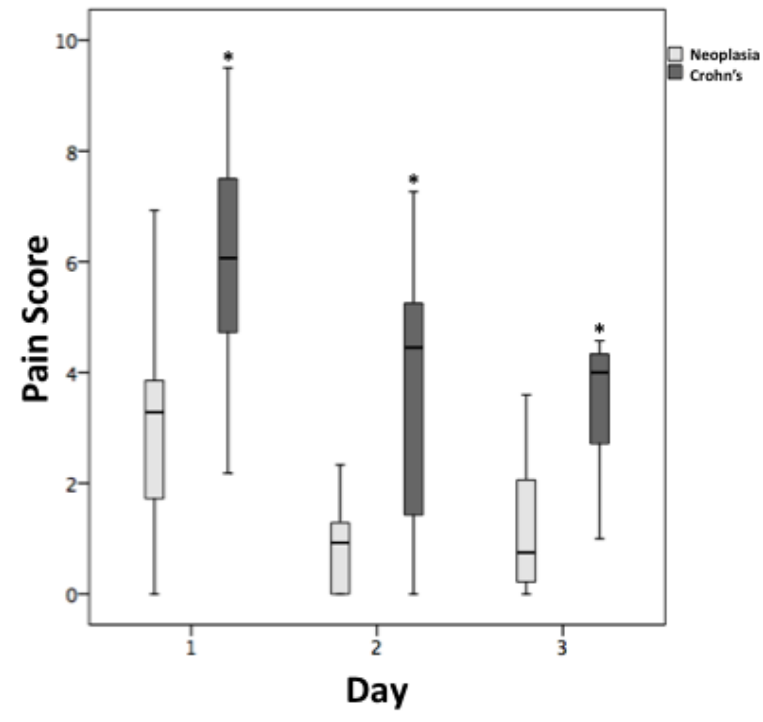

Figure 1. - Post-operative pain scores. Data are median/ interquartile range, and $95 \%$ confidence intervals are indicated by error bars. ${ }^{*} \mathrm{P}<0.05$, ANOVA.

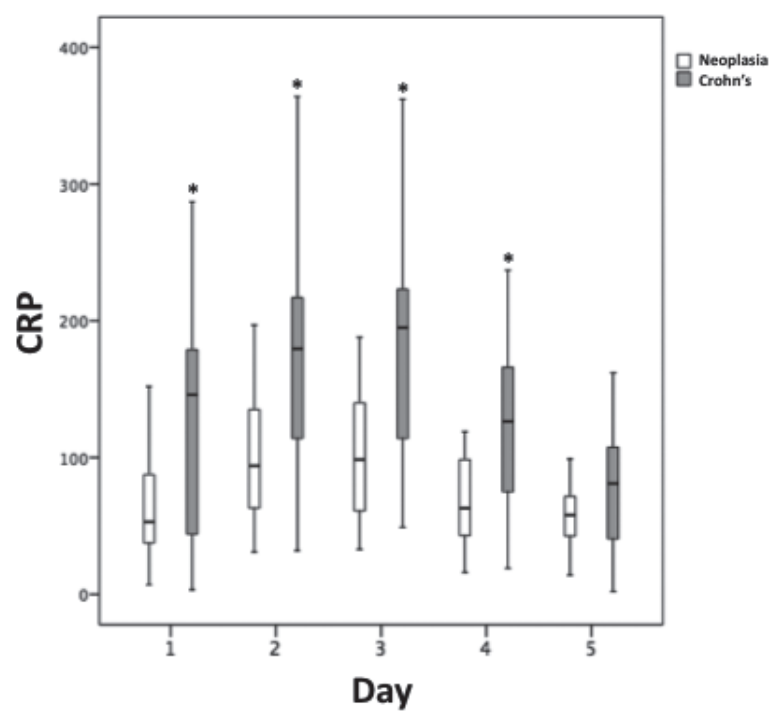

Figure 2. - Post-operative serum CRP. Data are median/ interquartile range, and $95 \%$ confidence intervals are indicated by error bars. ${ }^{*} \mathrm{P}<0.05$, ANOVA.

$\mathrm{P}=0.008$ ) (Figure 1). $\mathrm{CD}$ patients used their PCA for longer $(85.7 \pm 16.3 \mathrm{Vs} 47.7 \pm 4.2$ hours, $\mathrm{P}=0.017)$ and used a greater total amount of morphine $(148.6 \pm 33.8 \mathrm{Vs}$ $37.0 \pm 7.8 \mathrm{mg}, \mathrm{P}<0.001)$.

\section{Post-operative CRP levels}

Post-operative CRP levels were higher in patients with $\mathrm{CD}$ on day $1(124.1 \pm 42.3 \mathrm{Vs} 64.6 \pm 21.4, \mathrm{P}=0.011)$, day 2 (179.5 \pm 38.3 Vs $100.9 \pm 23.6, \mathrm{P}=0.001)$, day $3(182.6 \pm 43.8$ Vs $100.9 \pm 20.1, \mathrm{P}=0.001)$ and day $4(124.4 \pm 32.6 \mathrm{Vs}$ $72.2 \pm 19.3, \quad \mathrm{P}=0.007)$, compared to those neoplasia 
Table 1. - Baseline characteristics of study population

\begin{tabular}{|c|c|c|c|}
\hline Patient demographics & $\mathrm{CD}(\mathrm{n}=18)$ & Neoplasia $(n=20)$ & P-value \\
\hline Male/female (\%) & $10(56 \%) / 8(44 \%)$ & $12(60 \%) / 8(40 \%)$ & 0.520 \\
\hline Mean (SD) age, years & $39.8 \pm 2.8$ & $77.2 \pm 2.1$ & 0.001 \\
\hline $\begin{array}{l}\text { ASA grade, } n(\%) \\
-1 \\
-2 \\
-3\end{array}$ & $\begin{array}{c}4(22.2 \%) \\
13(72.2 \%) \\
1(5.6 \%)\end{array}$ & $\begin{array}{c}0 \\
11(55 \%) \\
9(45 \%)\end{array}$ & 0.005 \\
\hline $\begin{array}{l}\text { Pre-operative medications, } \mathrm{n}(\%) \\
\text { - Corticosteroids } \\
\text { - Mesalazine } \\
\text { - Sulfasalazine } \\
\text { - Azathioprine } \\
\text { - Methotrexate } \\
\text { - Infliximab } \\
\text { - Adalimumab } \\
\text { - Ustekinumab }\end{array}$ & $\begin{array}{c}10(55.5 \%) \\
1(5.6 \%) \\
1(5.6 \%) \\
3(16.7 \%) \\
2(11.2 \%) \\
7(38.9 \%) \\
7(38.9 \%) \\
1(5.6 \%)\end{array}$ & N/A & \\
\hline $\begin{array}{l}\text { Disease behaviour, n (\%) } \\
\text { - Fistulating } \\
\text { - Stricturing }\end{array}$ & $\begin{array}{l}9(50 \%) \\
9(50 \%)\end{array}$ & $\mathrm{N} / \mathrm{A}$ & \\
\hline $\begin{array}{l}\text { TNM classification, n (\%) } \\
\text { - T1 } \\
- \text { T2 } \\
\text { - T3 } \\
\text { - T4 } \\
\text { - N0 } \\
\text { - N1 } \\
\text { - N2 } \\
\text { - N3 }\end{array}$ & $\begin{array}{c}1(5 \%) \\
4(20 \%) \\
12(60 \%) \\
3(15 \%) \\
15(75 \%) \\
2(10 \%) \\
3(15 \%) \\
0\end{array}$ & N/A & \\
\hline $\begin{array}{l}\text { Location of tumour, n (\%) } \\
\text { - Caecum } \\
\text { - Ascending colon } \\
\text { - Hepatic flexure }\end{array}$ & $\begin{array}{l}12(60 \%) \\
5(25 \%) \\
3(15 \%)\end{array}$ & N/A & \\
\hline $\begin{array}{l}\text { Dindo-Clavien morbidity score, } \mathrm{n}(\%) \\
-1 \\
-2\end{array}$ & $\begin{array}{l}3(16.7 \%) \\
2(11.2 \%)\end{array}$ & $\begin{array}{c}1(5.6 \%) \\
0\end{array}$ & 0.667 \\
\hline Length of stay (SD), days & $7.2 \pm 0.5$ & $8.6 \pm 0.8$ & 0.153 \\
\hline
\end{tabular}

(Figure 2). No anastomotic leak or intra-abdominal abscess occurred in either group.

\section{Discussion}

The current study demonstrates that CD patients experience significantly more pain and require more post-operative analgesia as well as display an enhanced inflammatory response following elective laparoscopic right hemicolectomy, compared to patients with neoplasia undergoing the same operation performed by the same surgeon. However, it is important to mention that pain scores and CRP levels were not assessed preoperatively in any of the patients and that some Crohn's patients may have been suffering from pain at baseline due to presence of subacute bowel obstruction due to intestinal strictures and/or abscesses. To our knowledge, this is the first study to demonstrate this finding.

One previous study compared intra-operative sufentanil (an opiod pharmacotherapeutic agent) requirements between $\mathrm{CD}$, ulcerative colitis and control patients undergoing surgery, and showed increased sufentanil consumption during surgery in the IBD cohort (8). Plasma levels of alpha ${ }_{1}$-glycoprotein acid, an opiodbinding protein has also been shown to be significantly elevated in $\operatorname{IBD}(9,10)$. Interestingly, the increased opiod requirement in IBD patients was maximal during abdominal wall skin incision and closure. The authors attributed this to somatic hyperalgesia originating from referred dermatomes of diseased small intestine and colon.

The mechanism of this IBD-associated hyperalgesia is yet to be elucidated although work in murine models of colitis has shown heightened levels of Cathepsin-S, a lysosomal cysteine protease enzyme, in the colonic lumen during inflammation Cathepsin-S was activated in macrophages during colitis, secreted in the colonic lumen and resulted in colonic pain via hyperexcitability of colonic nociceptive neurons via a protease-activated-2 $\left(\mathrm{PAR}_{2}\right)$ dependent mechanism (11). Furthermore, antagonism of cysteine Cathepsin-S mitigated colonic inflammatory pain (11). These findings point to this specific protease as a pain mediator in colitis. However, the exact aetiology of the observed amplified pain response in post-operative $\mathrm{CD}$ patients remains unknown. Our series also demonstrated a significantly increased inflammatory response after surgery for $\mathrm{CD}$, compared to neoplasia. Levels of the acute phase protein CRP were significantly higher on post-operative days 1-4. These findings corroborate those of a previous study in which 
post-operative CRP levels in CD were on average $27 \%$ higher than in colonic neoplasia patients. 5 Other series have confirmed an accentuated inflammatory response associated with $\mathrm{CD}(4,12)$. The mechanism underpinning this pronounced post-operative inflammatory response may be partly explained by an exaggerated bacterial translocation and decortication of associated abscesses. Bacterial translocation is commonly observed in CD (4, 13) where intestinal microbiota and their by-products migrate out of the intestinal lumen into extraluminal sites such as mesenteric lymph nodes and blood (14) and generate a sustained cytokine response, thereby perpetuating the inflammatory state. It is postulated that an enhanced gut mucosal permeability facilitates the translocation of these bacteria $(15,16)$. Recently the relationship between bacterial translocation and postoperative outcomes in $\mathrm{CD}$ has been investigated. Li et al. showed that the presence of pre-operative bacterial DNA in blood of CD patients undergoing surgery was associated with a significantly increased rate of postoperative wound infections as well as longer hospital stay and increased readmission rates, compared to $\mathrm{CD}$ patients without bacterial translocation (17). These findings are consistent with those of a previous study and highlight the fact that bacterial DNA in CD patients may predispose them to post-operative systemic inflammatory response syndrome (4).

Our study is not without limitations. Firstly, it is a retrospective single-centre study with inherent bias pertaining to data collection and it also suffers from a small sample size. However, it captures all elective laparoscopic right colectomies for $\mathrm{CD}$ and neoplasia performed by the same surgeon in a standardised way during the study period and therefore allows meaningful comparisons to be drawn regarding post-operative patient outcomes. Secondly, we did not employ a validated pain assessment tool such as Visual Analogue Scale but instead relied on a numerical scale. However, quantifying and measuring the amount of intravenous morphine used by the patients in the post-operative period provides an objective assessment of the respective analgesic requirements in the two study cohorts. In summary, our data demonstrate that $\mathrm{CD}$ patients require significantly more post-operative analgesia following elective laparoscopic right colectomy compared to colonic neoplasia patients. Further studies in a larger cohort and assessment of analgesic requirements specific to other colorectal surgical procedures as well as during endoscopy are warranted to confirm this finding. Moreover, efforts to elucidate the aetiology of this hyperalgesia and mechanisms to negate it are required.

Author Contribution : Study design and data analysis : JPB, SG ; Patient recruitment : KM, SMS, SP, AO, JPB ; Data collection : KM, SMS, SG; Writing of the first draft of the paper: KM, SMS, SP, AO, SG, JPB.

Funding : no specific funding was received for this study.
Conflict of interest : none to declare.

Competing interests : The authors declare no competing interests. Paper presented in part at $13^{\text {th }}$ Congress of ECCO (P618), Vienna, Feb 2018.

\section{References}

1. TORRES J., MEHANDRU S., COLOMBEL J.F., PEYRIN-BIROULET L. Crohn's disease. Lancet. $2017 ; \mathbf{3 8 9}(10080)$ : 1741-55.

2. COSNES J., BOURRIER A., NION-LARMURIER I., SOKOL H., BEAUGERIE L., SEKSIK P. Factors affecting outcomes in Crohn's disease over 15 years. Gut. $2012 ; 61(8): 1140-5$.

3. BURKE J.P., VELUPILLAI Y., O'CONNELL P.R., COFFEY J.C. National trends in intestinal resection for Crohn's disease in the post-biologic era. Int. J. Colorectal. Dis. $2013 ;$ 28(10) :1401-6.

4. TAKESUE Y., OHGE H., UEMURA K., IMAMURA Y., MURAKAMI Y., YOKOYAMA T., et al. Bacterial translocation in patients with Crohn's disease undergoing surgery. Dis. Colon Rectum. 2002 ; 45(12) :1665-71.

5. DE BUCK VAN OVERSTRAETEN A., VAN HOEF S., VERMEIRE S., FERRANTE M., FIEUWS S., WOLTHUIS A., et al. Postoperative Inflammatory Response in Crohn's Patients : A Comparative Study. J. Crohns Colitis. 2015 ; 9(12) :1127-31.

6. MAYER E.A., GEBHART G.F. Basic and clinical aspects of visceral hyperalgesia. Gastroenterology. $1994 ;$ 107(1) :271-93.

7. DINDO D., DEMARTINES N., CLAVIEN P.A. Classification of surgical complications: a new proposal with evaluation in a cohort of 6336 patients and results of a survey. Ann. Surg. 2004; 240(2):205-13.

8. GUIDAT A., FLEYFEL M., VALLET B., DESREUMAUX P., LEVRON J.C., GAMBIEZ L., et al. Inflammation increases sufentanil requirements during surgery for inflammatory bowel diseases. Eur. J. Anaesthesiol. 2003 ; 20(12) :957-62.

9. WEEKE B., JARNUM S. Serum concentration of 19 serum proteins in Crohn's disease and ulcerative colitis. Gut. 1971 ; 12(4) :297-302.

10. PETTIT S.H., HOLBROOK I.B., IRVING M.H. Comparison of clinical scores and acute phase proteins in the assessment of acute Crohn's disease. Br. J. Surg. $1985 ;$ 72(12) : 1013-6.

11. CATTARUZZA F., LYO V., JONES E., PHAM D., HAWKINS J., KIRKWOOD K., et al. Cathepsin S is activated during colitis and causes visceral hyperalgesia by a PAR2-dependent mechanism in mice. Gastroenterology. $2011 ;$ 141(5): 1864-74 e1-3.

12. GUTIERREZ A., HOLLER E., ZAPATER P., SEMPERE L., JOVER R., PEREZ-MATEO M., et al. Antimicrobial peptide response to blood translocation of bacterial DNA in Crohn's disease is affected by NOD2/ CARD15 genotype. Inflamm. Bowel Dis. $2011 ; 17(8)$ :1641-50.

13. O'BRIEN C.L., PAVLI P., GORDON D.M., ALLISON G.E. Detection of bacterial DNA in lymph nodes of Crohn's disease patients using high throughput sequencing. Gut. $2014 ; \mathbf{6 3}(10): 1596-606$.

14. LAFFINEUR G., LESCUT D., VINCENT P., QUANDALLE P., WURTZ A., COLOMBEL J.F. [Bacterial translocation in Crohn disease]. Gastroenterol. Clin. Biol. $1992 ; \mathbf{1 6}(10): 777-81$.

15. GUTIERREZ A., SCHARL M., SEMPERE L., HOLLER E., ZAPATER P., ALMENTA I., et al. Genetic susceptibility to increased bacterial translocation influences the response to biological therapy in patients with Crohn's disease. Gut. $2014 ; \mathbf{6 3}(2): 272-80$.

16. CUNNINGHAM M.F., DOCHERTY N.G., BURKE J.P., O'CONNELL P.R. S100A4 expression is increased in stricture fibroblasts from patients with fibrostenosing Crohn's disease and promotes intestinal fibroblast migration. Am. J. Physiol. Gastrointest. Liver Physiol. 2010 ; 299(2) : G457-66.

17. LI Y., ZUO L., ZHU W., GONG J., ZHANG W., GU L., et al. The impact of bacterial DNA translocation on early postoperative outcomes in Crohn's patients undergoing abdominal surgery. J. Crohns Colitis. 2015 ; 9(3) :25965. 